ORIGINAL ARTICLE

\title{
Should a Study of Monoclonal Gammopathy of Undetermined Significance Be of Clinical Interest to Predict Myeloma Overcome?
}

\author{
J Véronique-Baudin ${ }^{1}$, O Pierre-Louis ${ }^{1,2}$, J Smith-Ravin ${ }^{3}$, M Vestris ${ }^{1}$, M Rose ${ }^{1}$, J-C Méniane ${ }^{4}$, J Macni ${ }^{5}$, C Joachim ${ }^{1}$, \\ P Escarmant $^{6}$, M-S Pierre-Louis ${ }^{2}$
}

\begin{abstract}
The majority of monoclonal gammopathy of undetermined significance (MGUS) are benign forms that require no treatment but can be considered as a pre-cancerous state. Monoclonal gammopathy of undetermined significance is quite frequent, and related to age. The risk of progression to multiple myeloma or another type of malignant lymphoproliferation is estimated at 1\% per year. Monoclonal gammopathy of undetermined significance is twice as frequent in patients of African descent, and prevalence is higher for men. Diagnosis of MGUS is made on evidence of a monoclonal component $<$ $30 \mathrm{~g} / \mathrm{L}$ and no CRAB criteria (hypercalcaemia, renal insufficiency, anaemia, bone lesions). Regular monitoring is required for all MGUS because they can develop into other lymphoproliferative disorders such as multiple myeloma and lymphoma and other haematologic malignancies. In view of the genetic, insular and environmental context specificities of Caribbean populations of African descent, and according to haemophilia trends of the French West Indies cancer registry, it will be interesting to determine incidence and prevalence of MGUS in a country in the Caribbean. No such study has been performed to date. There is a hypothesis for a possible geographic distribution of these blood disorders linked to environmental exposure to pesticides. The expected findings and their potential repercussions will have major public health interest, and should form the basis for a wider prognostic study to determine risk factors for MGUS in the French Caribbean. In a real life exhaustive study, the Martinique Cancer Registry proposes an epidemiological focus on MGUS in Martinique.
\end{abstract}

Keywords: Haematology, French West Indies, MGUS, monoclonal gammopathy of undetermined significance, risk factors

WIMJ Open 2016; 3 (1): 15

From: ${ }^{1}$ University Hospital of Martinique, UF1441 Oncology Research and Martinique General Cancer Registry; Oncology, Hematology, Urology and Pathology Department; Pierre Zobda Quitman Hospital CS90632 97261 Fort de France Cedex, ${ }^{2}$ University Hospital of Martinique, UF3237 Haemophilia Treatments Regional Center; Oncology, Hematology, Urology and Pathology Department; Pierre Zobda Quitman Hospital CS90632 97261 Fort de France Cedex, ${ }^{3}$ French West Indies University, Martinique, EA929 AIHP-Géode-BIOSPHERES, 97233 Schoelcher, Martinique, ${ }^{4}$ University Hospital of Martinique, UF2131, Oncology, Hematology, Urology and Pathology Department; Pierre Zobda Quitman Hospital CS90632 97261 Fort de France Cedex, ${ }^{5}$ Martinique General Cancer Registry, AMREC, Les Jardins de la Mouïna, 97200 Fort de France and ${ }^{6}$ University Hospital of Martinique, Oncology, Hematology, Urology and Pathology Department; Pierre Zobda Quitman Hospital CS90632 97261 Fort de France, Cedex.

Correspondence: Dr J Véronique-Baudin, University Hospital of Martinique, UF1441 Oncology Research and Martinique General Cancer Registry; Oncology, Hematology, Urology and Pathology Department; Pierre Zobda Quitman Hospital CS90632 97261, Fort de France Cedex. E-mail: jacqueline.baudin@chu-fortdefrance.fr

\section{INTRODUCTION}

Monoclonal gammopathy of undetermined significance (MGUS) is an asymptomatic condition in which there is an anomaly in the production of a monoclonal immunoglobulin (McIg), resulting in excess levels in blood or urine of abnormally high levels of an immunochemical type of Ig reflecting lymphoplasmacytic proliferation. Indeed, only production by strictly identical cells, monoclonal cells (1), can justify the presence of $\mathrm{Ig}$ with strictly identical properties. Detection of this McIg is most often achieved using protein electrophoresis, with a characteristic narrow band in the d-globulin zone (1). Protein electrophoresis makes it possible to identify McIg corresponding type of heavy $(\mathrm{G}, \mathrm{A}, \mathrm{M}, \mathrm{D}, \mathrm{E})$ or light $(\mathrm{k}, \mathrm{l})$ chain and provides information about the magnitude of the monoclonal peak. The diagnosis of MGUS is made after documentation of a 
peak of McIg by protein electrophoresis $(<30 \mathrm{~g} / \mathrm{L})$, in the absence of any clinical signs of malignant haemopathy, autoimmune disease or viral infection such as HIV or hepatitis C. In rare cases, an isolated monoclonal light chain can be detected, and, in the absence of renal failure, can be detected in the urine only (Bence-Jones protein). This warrants performing blood and urine immuno-electrophoresis, for the detection of an McIg. (2).

Most MGUS are benign forms that require no treatment, but close monitoring is necessary due to the nonnegligible risk of progression to overt malignant disease. Monoclonal gammopathy of undetermined significance can transition to multiple myeloma $(3,4)$, which is a malignant haemopathy characterized by clonal impairment and excessive production of medullary plasmocytes, which are responsible for production of McIg. The predictive factors of progression to malignant disease remain poorly documented, and are most often associated with deregulation of the medullary microenvironment function, responsible for efficacious haematopoiesis and homeostatic balance in the bone tissue. For this reason, MGUS can be considered as a pre-cancerous state. The magnitude of the McIg peak at the time of diagnosis, and the Ig isotype are predictors of progression to malignant disease.

\section{Clinical and biological context Epidemiology}

Monoclonal gammopathy of undetermined significance is an asymptomatic condition in which there is abnormal production of an McIg, with resulting excess levels found in the blood and/or urine. This deregulation of the globulinaemia represents a pathological situation in which there is overproduction of McIg by malignant plasma cells. The diagnosis of MGUS is based on demonstration of a peak of McIg on protein electrophoresis in the absence of any clinical signs of lymphoid haematological neoplastic disorders (1). The magnitude of the monoclonal peak at the time of the diagnosis, and the isotype are predictive factors of transition to malignant disease. The majority of MGUS are benign forms that require no treatment. However, regular monitoring is required for all MGUS (5).

Monoclonal gammopathy of undetermined significance primarily affects elderly subjects, and prevalence increases with age $[1-2 \%$ among subjects aged 50 to 60 years, $\sim 5 \%$ of patients aged 60 to 75 years, and $10 \%$ of subjects over 80 years of age] (6). Seventy per cent of McIg are $\operatorname{IgG}$ (d heavy chains), 15\% are IgA (a heavy chains), and $15 \%$ are IgM ( $\mathrm{m}$ heavy chains); biclonal gammopathies are exceptional. The light chain type is $\mathrm{k}$ in $60 \%$ of subjects, and 1 in $40 \%$. As for multiple myeloma, MGUS is twice as frequent in subjects of African American or mixed race origin. Prevalence is higher in men than in women. The risk of progression of MGUS to multiple myeloma is approximately $1 \%$ per year. The epidemiology of McIg in haematological hospital wards is over-represented since malignant pathologies are frequently observed in this context. Monoclonal gammopathy of undetermined significance can also develop into other lymphoproliferative disorders such as lymphoma (2).

This disease is all the more serious in patients with early onset, or with late diagnosis (elderly patients). A minimum of biological examinations is necessary in asymptomatic patients to rule out a latent myeloma (5). Clinical history taking should look for bone pain or recurrent infection. Once the diagnosis of MGUS is confirmed, the patient should be informed about the need for a clinical plus biological check-up twice a year, in view of the risk of transition to malignant disease. Rare occurrences of very rapid development to malignancy call for re-evaluation in case of the sudden appearance of clinical symptoms. The role of obesity should also be considered as a potential risk factor associated with the development of MGUS.

\section{Aetiologic context}

The presence of McIg reflects proliferation of clonal plasma cells. Although this monoclonal status may correspond to malignant cell proliferation [multiple myeloma, Waldenstrom macroglobulinaemia, chronic lymphoid leukaemia, non-Hodgkin's lymphoma, myelodysplastic syndrome] (7), it is frequent that extensive investigations fail to find any sign of these diseases. However, long-term monitoring of the socalled benign gammopathy brought to light a risk of transition to malignant disease of approximately $1 \%$ per year. This led to the introduction of the term MGUS, in order to take into consideration the potential risk of deterioration, however small that risk may be (2).

The occurrence of MGUS could be linked to several factors such as environmental factors, viral factors, pathophysiological predisposition, genetic or epigenetic predispositions.

Environmental factors: Exposure to chemicals, particularly pesticides, could contribute to the transition from MGUS to malignant disease $(8,9)$, especially in elderly patients who have been chronically exposed to such risk factors throughout their lives. Pesticides remain a major public health challenges as they could be related to the occurrence of epigenetic deregulation, and secondarily, to the occurrence of certain types of cancer. According to the regional federation for defence against harmful organisms, potentially toxic chemical agents include molecules used in banana plantations that have been recently been banned, weedkillers $\left(\right.$ Karmex $^{\circledR}$, Ouragan $^{\circledR}$, R-Bix $\left.{ }^{\circledR}\right)$, fungicides $\left(\right.$ Baycor $\left.^{\circledR}\right)$, nematicides and insecticides (Rugby 10G ${ }^{\circledR}$, Mocap 10G $R^{\circledR}$ ), weedkillers used in sugar plantations, also recently banned, Calliherbe ${ }^{\circledR}$, Dico Pur CL ${ }^{\circledR}$, Karmex $^{\circledR}$, Novflex ${ }^{\circledR}$, Flo80 ${ }^{\circledR}$, Velpar $\mathrm{S}^{\circledR}$, Asulox ${ }^{\circledR}$, Weedone ${ }^{\circledR}$. In a French West Indies Caribbean area, such as Martinique, the ten most widely sold active substances were weedkillers (glyphosate, glufosinate ammonium, asulame, 2, 4-d, s-metolachlore, diquat), nematicides (oxamyl, fosthiazate) and fungicides 
[difenoconazole, mancozebe] (10).

Viral factors: Some authors $(11,12)$ have shown that the human herpes virus 8 (HHV-8), found in Kaposi's sarcoma, the hepatitis $\mathrm{C}$ virus and the Epstein-Barr virus, could be associated with MGUS. However, the pathophysiological mechanisms remain unclear. Monoclonal gammopathy of undetermined significance should be diagnosed outside the infection context.

Pathophysiological predisposition: In physiological state, plasmocyte precursors are derived from lymphoid cells selected for their affinity to specific antigens. These plasma cells migrate in the blood to the bone marrow, where they make contact with the various components of the extracellular matrix and stromal cells. The cell contacts that are established between these pre-malignant cells and bone marrow stromal cells contrive to produce cellular costimulation phenomena, leading to increased secretion of growth factors (12-14). Interleukin-6 (IL6) is a cytokine that enhances formation of mature plasma cells, which are responsible for the secretion of immunoglobulins. In myeloma, the increased production of growth factors protects cancerous cells against apoptosis induced by chemotherapy (15). Deregulation of the cell and tissue interactions established by pre-malignant cells with the bone marrow microenvironment lead to the development of a malignant plasma cell clone, and secondarily, to the production of McIg (16). These pre-malignant processes can be reversed if an efficacious immune system performs its targeted anticancer functions.

Genetic or epigenetic predispositions: Identifying the nature and origin of plasma cell clone, as well as associated genetic mutations, could improve our understanding of precancerous development, although primarily acquired diseases, hereditary factors and ethnic origin (17) could play a crucial role in MGUS outcome. The most commonly observed cytogenetic anomalies in pre-myeloma are complex karyotypes (18), with numerous co-existing chromosome anomalies. We can distinguish between the following forms: (i) chromosomal translocations involving IgH locus (14q32). The partner genes are bcl-1, hyper-expression of cyclin-D1, or growth factors gene receptors. IgH locus abnormalities are frequently associated with the myeloma development (50 to $60 \%$ of cases), but not consistently; they do not constitute a marker of the disease. (ii) Other structural anomalies correspond to secondary events that are not specific to multiple myeloma, and acquired over the course of the disease. Anomalies in chromosome numbers are present in the majority of cases, but no chromosome is consistently implicated, although aneuploidies (19) are frequent. Genetic anomalies are often associated with oncogene dysregulation or tumour suppressor genes.

\section{CONCLUSION}

The results of a literature review revealed that MGUS monitoring could represent a major public health challenge.
In view of the genetic specificities of the Caribbean populations, the insular and environmental context, it will be interesting to determine by a cross-sectional aetiological study, the incidence and prevalence of MGUS in one country in the Caribbean, since no such study has been performed to date. The medium-term objective is to determine the biological parameters that can determine which patients will remain asymptomatic and which will go on to develop malignant disease.

The study of MGUS in the French West Indies area for the first time, according to the French West Indies cancers registries, will be a real new challenge and motivated by the need to understand the development of the precancerous state, and it should be based on diagnosis, epidemiological data, aetiological factors, and clinical follow-up.

The expected findings and their potential repercussions would have major public health interest, and should form the basis for the first time in the Caribbean, a wider prognostic study to determine risk factors for MGUS that are associated with a pre-malignant disease state, in order to support the hypothesis of a possible geographic distribution of these blood disorders linked to environmental exposure to pesticides.

\section{ACKNOWLEDGMENTS}

This work was supported by Martinique Hematology Association, West Indies, University Hospital's Oncology, Hematology, Urology and Pathology Department and the Oncology network. All authors contributed equally to the manuscript. The authors deny any conflict of interest or receipt of funds from any sources.

\section{REFERENCES}

1. Klein E, Ronez E, Drouet L. Major plasma cells' dystrophy in monoclonal gammopathy of undeterminated significance. Eur J Haematol 2012; 88: 461-9

2. Wu B, Chen P, Wang W, Li F, Zou S, Cheng Y. IgA monoclonal gammopathy accompanying extranodal B cell lymphomas. Ann Hematol 2014; 93: 521-2.

3. Agarwal A, Ghobrial M. Monoclonal gammopathy of undetermined significance and smoldering multiple myeloma: a review of the current understanding of epidemiology, biology, risk stratification, and management of myeloma precursor disease. Clin Cancer Res 2013; 19: 985-94.

4. Schleiffenbaum BE. [Monoclonal gammopathy of undetermined significance (MGUS) and multiple myeloma]. Praxis (Bern 1994) 2012; 101: 1521-9; quiz 1530-1. doi: 10.1024/1661-8157/a001137.

5. Hübel K, Hallek M. Monoclonal gammopathy of undetermined significance and monoclonal B-lymphocytosis. Internist (Berl) 2013; 54: 709-14.

6. Wadhera RK, Rajkumar SV. Prevalence of monoclonal gammopathy of undetermined significance: a systematic review. Mayo Clinic Proc 2010; 85: 933-42. doi: 10.4065/mcp.2010.0337. Epub 2010 Aug 16.

7. Roeker LE, Larson DR, Kyle RA, Kumar S, Dispenzieri A, Rajkumar SV. Risk of acute leukemia and myelodysplastic syndromes in patients with monoclonal gammopathy of undetermined significance (MGUS): a population-based study of 17315 patients. Leukemia 2013; 27: 13913. doi: 10.1038/leu.2013.34. Epub 2013 Feb 5.

8. Landgren O, Kyle RA, Hoppin JA, Beane Freeman LE, Cerhan JR, Katzmann JA et al. Pesticide exposure and risk of monoclonal 
gammopathy of undetermined significance in the Agricultural Health Study. Blood 2009; 113: 6386-91.

9. Pasqualetti P, Collacciani A, Casale R. Risk of monoclonal gammopathy of undetermined significance: a case-referent study. Am J Hematol 1996; 52: 217-20.

10. Fédération Régionale de Défense contre les Organismes Nuisibles FREDON. Fort de France: Fédération Régionale de Défense contre les Organismes Nuisibles de la Martinique; 2006. 488. Available from: http://catalogue.bnf.fr/ark:/12148/cb14571335r

11. Beksac M, Ma M, Akyerli C, DerDanielian M, Zhang L, Liu J et al. Frequent demonstration of human herpes virus 8 (HHV-8) in bone marrow biopsy samples from Turkish patients with multiple myeloma (MM). Leukemia 2001; 15: 1268-73.

12. Babel N, Schwarzmann F, Pruss A, Volk HD, Reinke P. Monoclonal gammopathy of undetermined significance (MGUS) is associated with an increased frequency of Epstein-Barr virus (EBV) latently infected B lymphocytes in long-term renal transplant patients. Transplant Proc 2004; 36: 2679-82.

13. Edwards CM, Zhuang J, Mundy GR. The pathogenesis of the bone disease of multiple myeloma. Bone 2008; 42: 1007-13.

14. Zdzisińska B, Bojarska-Junak A, Dmoszyńska A, Kandefer-Szerszeń M. Abnormal cytokine production by bone marrow stromal cells of multiple myeloma patients in response to RPMI8226 myeloma cells. Arch Immunol Ther Exp (Warsz) 2008; 56: 207-21.

15. Scudla V, Ordeltova M, Bacovsky J, Vytrasova M, Horak P, Minarik J. The relationship between proliferation and apoptosis in patients with monoclonal gammopathy of undetermined significance or multiple myeloma. Haematologica 2005; 90: 1713-4.
16. Corre J, Mahtouk K, Attal M, Gadelorge M, Huynh A, FleuryCappellesso $\mathrm{S}$ et al. Bone marrow mesenchymal stem cells are abnormal in multiple myeloma. Leukemia 2007; 21: 1079-88.

17. Baker A, Braggio E, Jacobus S, Jung S, Larson $D$, Therneau $T$ et al. Uncovering the biology of multiple myeloma among African Americans: a comprehensive genomics approach. Blood 2013; 121: 3147-52.

18. Kuehl WM, Bergsagel PL. Molecular pathogenesis of multiple myeloma and its premalignant precursor. J Clin Invest 2012; 122: 3456-63.

19. Königsberg R, Ackermann J, Kaufmann H, Zojer N, Urbauer E, Krömer E et al. Deletions of chromosome 13q in monoclonal gammopathy of undetermined significance. Leukemia 2000; 14: 1975-9.

Received 03 Aug 2015

Accepted 11 Sep 2015

Published 09 Feb 2016

Online: http://www.mona.uwi.edu/wimjopen/article/1663

(C) Véronique-Baudin et al 2016.

This is an open access article made freely available under Creative Commons Attribution 4.0 International (CC BY 4.0). Users are free to share, copy and adapt this work as long as the copyright holder (author) is appropriately and correctly credited. See http://creativecommons.org/ licences/by/4.0/deed.en_us for more information. 